\title{
Dionísio e o mistagogo: apontamentos sobre a questão do parricídio filosófico
}

\author{
Dionysus and the mystagogue: notes on the \\ question of a philosophical parricide
}

\section{Eduardo Ribeiro da Fonseca}

Doutor em Filosofia Moderna e Contemporânea pela Universidade de São Paulo (USP), professor de Filosofia da Pontifícia Universidade Católica do Paraná (PUCPR), Curitiba, PR - Brasil, e-mail: eduardorfonseca@uol.com.br

\section{Resumo}

Em Schopenhauer, o sofrimento existencial ligado à recorrência do desejo cessa apenas, parcialmente, nos momentos de contemplação artística, ou, de modo mais amplo e profundo, na negação (Verneinung) da Vontade. Isto se traduz na condenação ética ao aspecto compulsivo da atividade da Vontade. Em Nietzsche, inversamente, a intensificação é parte da referência comum aos impulsos (Triebe) por poder, pois estes até mesmo buscam o que lhes resiste, formando soluções de compromisso e combatendo entre si, restando também uma possibilidade de refinamento dos alvos dos impulsos. A diferença em relação ao inevitável sofrimento admitido por ambos é que Nietzsche se recusa à compaixão 
e à negação da Wille zum Leben. A questão que analisamos neste artigo é se, apesar disso, não haverá alguma injustiça na visão de Nietzsche acerca de Schopenhauer, precisamente no que concerne ao fato do primeiro ser a fonte originária do pensar acerca dos impulsos inconscientes, e em que medida, apesar do "parricídio" em relação ao grande mestre de sua juventude, Nietzsche não terá preservado involuntariamente em sua filosofia muito mais de Schopenhauer do que poderia admitir.

Palavras-chave: Impulso. Vontade. Inconsciente.

\section{Abstract}

In Schopenhauer, the existential suffering associated with recurrence of desire ceases only partially in moments of artistic contemplation, or, more widely and deeply in denial (Verneinung) of the Will. This translates into the ethical condemnation of the compulsive aspect of the activity of the Will. In Nietzsche, conversely, the intensification is part of the common reference of the drives (Triebe) for power, even as they seek to resist it, forming compromise solutions and fighting among themselves, also leaving the possibility of refining the targets of impulses. The difference relative to the inevitable suffering that is accepted by both is that Nietzsche refuses the compassion and the denial of $W$ ille zum Leben. The question analyzed in this article is whether, despite this, there will be no injustice in Nietzsche's view about Schopenhauer, specifically regarding the fact that the first being the original source of thinking about the unconscious impulses, and to what extent, despite the "patricide" in relation to the great master of his youth, Nietzsche will not unintentionally preserved in its philosophy much more of Schopenhauer than he could admit.

Keywords: Drive. Will. Unconscious.

Nietzsche descobre a filosofia de Schopenhauer em 1866. Segundo sua própria narrativa, tal encontro foi marcado por profundo júbilo e produziu uma grande mudança em sua vida, equivalente a uma conversão e a 
uma iniciação filosófica. Três anos depois, pouco antes de assumir a cátedra de filologia clássica, escreve a um amigo, dizendo que, graças a Schopenhauer, a filosofia se enraizou nele de modo profundo: "o grande mistagogo (großen Mystagogen) Schopenhauer mostrou-me com farta clareza os verdadeiros e essenciais problemas da vida". O filósofo de Frankfurt é comparado a um sacerdote, a alguém que inicia o jovem Nietzsche nos mistérios da filosofia. Para o autor de Ecce Homo, naquele momento crucial de sua vida, a obra de Schopenhauer opera como um significante, na medida em que o jovem filólogo pretende superar o problema da linguagem, privilegiando o pensamento a partir do conhecimento imediato do mundo. ${ }^{1}$ Isso foi algo tão determinante para o autor do Zaratustra, que mesmo anos mais tarde, quando já se apresenta como um antagonista do pessimismo teórico de Schopenhauer, ainda faz elogios pontuais ao seu antigo e já renegado mestre:

[...] O seu duro senso dos fatos, sua honesta vontade de clareza e razão, que com frequência o faz parecer tão inglês e tão pouco alemão [...]. O vigor de sua consciência intelectual [...]. Suas imortais teorias da intelectualidade da intuição, da natureza instrumental do intelecto e da não-liberdade da vontade [...] (GC 99).

O acento schopenhaueriano sobre o caráter intelectual da intuição vai propor problemas próprios a Nietzsche, dentre os quais os relacionados às questões do pessimismo teórico, do inconsciente, do corpo como mestre da racionalidade e da consciência como qualquer coisa inacabada, servil e sintomática. Até mesmo nos aspectos em que Nietzsche negará o negador, também citados e enumerados no mesmo aforismo, ainda assim utilizará um instrumental analítico encontrado na obra do filósofo de Frankfurt, especialmente nos Complementos ao Mundo como Vontade e Representação.

A consciência aparece então como um sintoma, tanto no sentido do resultado de uma história e de uma experiência que lhe são peculiares, quanto no sentido de encarar o Eu - o principium individuationis - como a parte historicamente mais recente, imperfeita e inacabada, e por isso mesmo, mais problemática do psiquismo. À sombra da consciência, o instinto e o impulso inconscientes exigem um trabalho do intelecto, devido à urgência de satisfação. Por isso o ímpeto das paixões surge, desde os primórdios do dogmatismo filosófico, como o inimigo a ser combatido pelo homem.

1 JANZ, C. P. Friederich Nietzssche. 1. Infancia y juventud. Tradução espanhola de Jacobo Muñoz e Isidoro Reguera. Madrid, p. 160 ss. 
Ao ser submetido à necessidade de satisfação de desejos e necessidades, o intelecto exige um trabalho inverso que se resume na tentativa de dominar o próprio impulso.

É precisamente a partir desses elementos, ainda não devidamente articulados, que Nietzsche vai introduzir o problema do pessimismo. Ou, o pessimismo como um problema relacionado ao adoecimento da cultura. O retrato do mundo grego feito pelo jovem filólogo - especialmente a sua visão da arte grega - é o pano de fundo que vai dar suporte histórico e mesmo caracterizar uma postura investigativa que pretende reconhecer que o real efetivo não equivale à linguagem conceitual escolhida para a sua descrição. Ilusão, realidade, verdade, erro, belo e terrível, aparecem como uma ciranda de elementos contraditórios e necessários à ordem do mundo e ao discurso sobre o mundo: "Não há superfície bela (schöne Fläche) sem uma profundidade terrível (schreckliche Tiefe)" (FP de fim de 1870-abril de $18717[91])$.

O desejo e a esperança de Nietzsche, segundo carta da mesma época do fragmento citado acima, é o de infundir aos seus alunos esse mesmo fervor filosófico despertado nele pelo filósofo da Vontade, levando-os para além da filologia praticada em seu tempo. Isto é, o autor de Além do Bem e do Mal se recusa ao papel de mero instrutor de habilidades específicas no campo científico e tenta promover uma relação de ensino e aprendizagem que seja ela mesma arte e reflexão filosófica. Desse modo, a filosofia de Schopenhauer é a referência pessoal, mas também lhe parece o espelho mais fiel do mundo naquele momento (naquele breve instante da história da filosofia...). Através do que lê em Schopenhauer, Nietzsche tem elementos para pensar o que é o homem e recebe subsídios para se ocupar do problema do pessimismo, relacionando-o às vicissitudes de impulso (Trieb).

O modo como o autor do Zaratustra toma o conceito de impulso no texto sobre Homero e a Filologia Clássica, já modifica o acento característico da filosofia de Schopenhauer. A diferença é que em Schopenhauer o termo tinha uma aplicação definida, orgânica e consistente com o motivo fundamental da sua filosofia: o esclarecimento do conceito de Vontade na natureza, na antropologia e na fisiopsicologia do desejo individual. Em Nietzsche, pelo contrário, toda descrição do real é meramente alusiva e metafórica. A Filologia aparece como um amálgama heterogêneo de impulsos científicos e também éticos e estéticos que se resolvem em uma unidade apenas virtual e, do ponto de vista da linguagem, a partir de uma denominação 
comum, que cria, segundo o filósofo, uma espécie de monarquia aparente (Scheinmonarchie). ${ }^{2}$ Esse uso verdadeiramente sutil e inaugural do termo impulso acentua a hierarquização instável de forças e tendências sem uma unidade ontológica fundamental e introduz os modos futuros como o filólogo-filósofo se relacionará com o termo e o utilizará ao longo do tempo. É claro que tudo isso se origina do querer-viver schopenhaueriano, que expõe uma vontade cindida na efetividade, mas, Nietzsche vai explorar isso de seu próprio modo.

Essa monarquia aparente de tendências hegemônicas resulta na consideração de duas espécies mais genéricas de impulsos, os "científicos" e os "ético-estéticos" (wissenschaftlichen und ästhetisch-ethischen Triebe). A distinção ou categorização dos impulsos se dá a partir de sua forma de atividade ou expressão. Há impulsos específicos presentes na ciência, na ética e na arte. Como lembra Assoun, os impulsos referidos por Nietzsche se apresentam como "pequenos demônios que animam as atividades humanas" (ASSOUN, 2005, p. 78) ${ }^{3}$. Deve-se destacar em relação a isto a noção de composição ou amálgama entre diferentes impulsos. Toda atividade supostamente unitária, como a própria Filologia, resulta já da atração e da tensão de impulsos mantidos juntos (zusammengetan) ${ }^{4}$.

O que se chama 'realidade', ou, antes, 'efetividade', resulta inteira dessa diversidade conflituosa de impulsos, o que reduz a ideia de unidade a uma mera aparência, sob a qual há apenas tensões e soluções de compromisso entre impulsos. É desse ponto de partida que se organizará o modo próprio como Nietzsche questionará os filósofos em relação às questões da verdade, da essência e da linguagem próprias ao mundo. A homogeneidade resulta de uma "aparência" que encobre uma variedade complexa de impulsos mantidos juntos por força de uma "seleção" a partir de valores, que não tem nada de natural. Por isso a associação, no texto, entre "Filologia" e "Pedagogia": o

2 NIETZSCHE, F. Homer und die klassische Philologie.In: Werke:kritische Gesamtausgabe, volume II, parte I, Philologische Schriften, página 250.

3 A atividade específica é representada por um impulso, que Assoun compara à crença animista, na qual havia um espírito em cada objeto, e à visão heraclitiana de que há deuses em todo lugar. Pelo menos, há impulsos em tudo o que é importante.

4 Idem ibidem.A frase específica à qual eu me refiro no texto original de Nietzsche diz: „,...)Daß diese durchaus verschiedenartigen wissenschaftlichen und aestetisch-ethischen Triebe sich unter einen gemainsamen Namen, unter eine Art von Scheinmonarchie zusammengethan haben, wird vor allem durch die Thatsache erklärt, daß die Philologie ihrem Ursprunge nach und zu allen $\beta$ Zeiten zugleich Pädagogike gewesen ist". 
afã pedagógico obriga a uma seleção dos elementos edificantes, à maneira de Platão em $A$ República. Porém tal agregado se mostra um aglomerado de características inconciliáveis, que existe, porém, meramente como linguagem. Para Nietzsche, isto explica o estado de guerra entre os impulsos fundamentais (Grundtriebe) mantidos juntos à força e obrigados a coexistir na cultura (tema que depois será retomado por Freud em O Mal-estar na Cultura). Portanto, a natureza humana aparece como qualquer coisa extraordinariamente complexa e antinatural - uma natureza artística. Nietzsche fala, nesse sentido, da "hostilidade" (Feindseligkeit) ${ }^{5}$ de impulsos fundamentais mantidos juntos (zusammengefaßten) ${ }^{6}$ sob o nome de filologia.

Além de acentuar que a unidade característica dos impulsos é apenas aparente, e ligada ao hábito de pensamento e à linguagem, Nietzsche sugere também que essa unidade se dá à força e permanece em conflito sob a máscara da unidade. O regime anárquico é uma tendência originária, no sentido de 'anterior' àquelas tendências dos impulsos já modulados na cultura, que muitas vezes padecem de um desenvolvimento defletido em sintoma. A Filologia, por exemplo, é uma narrativa que resulta da fixação do olhar sobre os livros antigos de uma forma demasiado unilateral, que para se libertar disso, deve considerar as relações inconscientes envolvidas, isto é, as relações da personalidade individual com os impulsos inconscientes, e também as relações do indivíduo com os grandes impulsos massivos e populares. Homero é visto nessa hipótese nietzschiana como um médium na torrente dos impulsos artísticos impetuosos presentes na massa pré-histórica ${ }^{7}$.

Se com isto se percebe a fluidez das tendências, são esclarecidos também tanto os modos de fixação dos impulsos (Triebe) humanos na torrente dos instintos (Instinkte) perenes ${ }^{8}$ da natureza humana, quanto na sua irrupção dinâmica e subterrânea enquanto impulsos coletivos e individuais presentes no inconsciente popular. A mesma distinção entre instinto e impulso encontrada em Schopenhauer reaparece aqui. Tanto os "grandes instintos de massas" (großen Masseninstinkte) interessantes ao gênero

5 Idem, p. 251.

6 Idem Ibidem.

7 Idem, p. 259. Inversamente, a força da Ilíada e da Odisséia também aprisiona os impulsos do povo grego histórico, como se vê em: NIETZSCHE, F. Humano, demasiado bumano. São Paulo: Companhia das Letras, 2005, P. 166.

8 Idem, p. 260.

Estudos Nietzsche, Curitiba, v. 4, n. 1, p. 25-42, jan./jun. 2013 
humano e ao orgânico, quanto os impulsos populares inconscientes como atualidade de tendências no indivíduo humano - , são os "suportes" (Träger) e os "motores" (Hebel) da história do mundo (Weltgeschichte) ${ }^{9}$. Esta parece ser a fonte histórica, ou, o núcleo original, do conceito de vontade de potência nietzschiano. O homem é o demiurgo do próprio instinto artístico e lentamente o transforma, ao longo do imenso período pré-histórico, em impulso, pela arte da percepção do objeto belo e terrível, e de si mesmo, isto é, o homem que é o assimilador e o criador de mundos.

Segundo Assoun acertadamente observa, a prática filológica heterodoxa proposta por Nietzsche deve considerar três aspectos complementares uns aos outros: 1) O inconsciente como ação subterrânea de impulsos heterogêneos, operando nos registros científico, ético e estético; 2) A linguagem, objeto da Filologia, é também um impulso; 3) A Filologia capta, pela linguagem, as forças dos impulsos e instintos que atuam na história, sejam elas específicas ou coletivas (2005, p. 80).

O domínio violento sobre os impulsos, na verdade representa a preponderância de certas tendências valorizadas socialmente. E esse o ambiente em que a Filologia inscreve a sua visão necessariamente unilateral dos fatos. O filólogo, sabendo ou não, por utilizar a linguagem, por ser um organismo, está sujeito como tudo no mundo às mesmas forças que regem o instinto e o impulso, já que elas definem, em última instância, o que a filologia é, e também o seu objeto e propósitos inconscientes. Até Nietzsche, a filologia só entrava na oficina do instintivo (Werkstätte des Instinktiven) sem o saber. A partir deste texto, a Filologia deverá considerar instintos e impulsos, encontrando para si um objeto privilegiado na consciência grega.

O impulso guerreiro aparece como a fonte de vitalidade da civilização homérica e do gênio grego. Tal consideração não será esquecida por Nietzsche e terá suprema importância para o desenvolvimento posterior da sua filosofia.

Por outro lado, o impulso artístico aparece no texto como protótipo dos impulsos pela sua atividade formadora apolínea. Esse é um momento importante devido à associação do impulso à linguagem, propondo aparências ou formas artísticas para tudo, inclusive para os próprios impulsos. E é nesse ponto de suas articulações teóricas que o interesse de Nietzsche se volta ao dualismo dos impulsos que será investigado por ele em seguida.

9 Idem ibidem.

Estudos Nietzsche, Curitiba, v. 4, n. 1, p. 25-42, jan./jun. 2013 
É interessante notar como os interesses do Nietzsche filólogo vão lentamente, a partir de suas primeiras produções intelectuais, configurando uma visão estética dos Triebe - na qual arte e impulso são pontos de partida, porém não fundamentos - , que ao mesmo tempo em que o aproximam da análise psicológica do pessimismo, permitem a ele enlaçar a dor e o sofrimento humanos em uma visão da arte como redentora da consciência e da percepção a ela relacionada, que subordina o caos à beleza - como um triunfo do transitório. Tal triunfo não significa uma eliminação do sofrimento, pois tal coisa não é possível na perspectiva trágico-estética adotada por Nietzsche.

Esta resulta, pelo contrário, em uma compreensão da vida a partir de suas contradições fundamentais, aceitando os aspectos conflituosos que a compõem, que já estão dados na sua concepção original do Trieb. Deste modo, o artista trágico reconfigura a existência - em si mesma contingente, ilógica e dilacerante - em uma experiência de linguagem, que ao mesmo tempo em que contextualiza e confere lugar ao sofrimento, não permite dar a este uma interpretação moral.

Desse embrião surgirá uma obra que poderá lentamente - a partir de uma visão que concilia desejo e necessidade — colocar um véu de beleza sobre o terrível e propor esse gesto como uma característica essencial da tragédia grega clássica. Tal modo de ver as coisas tenta superar tanto o otimismo quanto o pessimismo diante do real, e simultaneamente reconstruir a crítica psicológica da linguagem, na qual se baseia a Filologia de Nietzsche, conferindo-lhe um estatuto não apenas interpretativo e metafórico, mas, além disso, positivo, como construção e característica da experiência passada, presente e futura do próprio real humano. A tal ponto que em Nietzsche não é mais possível separar da linguagem o mundo, o corpo, o intelecto e o impulso. Ao final, de aparência em aparência, de máscara em máscara ao fundo de outras máscaras, através do histórico das coisas em devir não se chega jamais a qualquer essência que não se configure novamente em um novo objeto brilhante que nos ilude e talvez nos cegue, como a mais pura arte na experiência.

Ao invés de suportar a solidão e o caos com temor e resignação, Nietzsche vai propor, através da arte transfigurada em experiência, mas também reconhecida como fundo da própria experiência, uma "grande saúde" que consiste basicamente em continuar inventando mundos para neles viver. Com isso, não apenas se resigna ao devir, mas o afirma 
incondicionalmente e dele retira a sua força, tal como fazia o trágico grego, dando a si mesmo e ao público um remédio para as terríveis dores do mundo e um alento contra o pessimismo. Com isso propunha um análogo do real, pois o real em si é incompreensível e insuportável: "A tragédia é o remédio natural (Naturheilkraft) contra o dionisíaco (Dionysische). É preciso vivê-lo: portanto, é impossível o puro (reine) dionisíaco. Pois o pessimismo é ilógico na teoria e na prática" (FP de 1869 3[32]). Trata-se da salvação da Vontade mediante a beleza, e da submissão incondicional ao contingente representado pelos deuses, com o que a Vontade, astuciosamente, adquire uma nova possibilidade de afirmação: "A vontade tende à cura, aos gozos supremos isentos de dor" (FP de $18707[100]$ ).

Assim o querer-viver tem necessidade das representações ilusórias para se transfigurar em arte. Tal passagem da vigília do real para o sonho da arte permite à consciência o grau de suportabilidade necessário que a cura de sua tristeza diante do terrível que representa a vontade para o indivíduo.

Traduzindo em linguagem freudiana, deparamo-nos com a tendência e com a dificuldade do sistema nervoso em dominar as cargas de excitação provenientes tanto do interior do organismo, quanto do seu exterior. Nesse caso, o enlace do real que torna possível e desejável a experiência, se dá através da arte. Nietzsche vai tentar representar essa visão redentora da arte como uma linguagem e como princípio de conhecimento através de uma visão econômica e dinâmica dos instintos e impulsos.

As leituras que levam este filósofo ao dualismo dos impulsos artísticos encontram correspondência no pessimismo schopenhaueriano, mas, também, segundo DIAS (2003, p.174), possibilitam a Nietzsche articular sua nova visão do trágico como enlace e superação da miséria e do terrível da existência. Dentre essas leituras de Nietzsche, segundo Andler (1958, p. 409), estão os livros de George Friederich Creuzer e Johann Jakob Bachofen, que ajudaram o jovem filólogo a pensar a antítese e a complementaridade entre Apolo e Dioniso ${ }^{10}$ Creuzer, em Simbolismo e Mitologia das Nações Antigas (escrito em 4 volumes, publicados entre 1819-23), descreveu tal relação como uma hostilidade profunda e originária, seguida de uma lenta reconciliação. A descrição que faz da relação entre os dois mitos

10 Nesse artigo, Dias segue os passos de Andler e analisa a influência de Creuzer e Bachofen na concepção nietzschiana dos impulsos artísticos fundamentais: "Nos perguntamos como esses conceitos apareceram em sua obra, como foram criados".

Estudos Nietzsche, Curitiba, v. 4, n. 1, p. 25-42, jan./jun. 2013 
estabelece um padrão de referência para que mais tarde Nietzsche possa pensar a natureza de seus dois impulsos artísticos fundamentais. Bachofen, por sua vez, em Simbolismo dos túmulos, de 1859, trata da mesma questão e foi lido por Nietzsche enquanto escrevia suas três conferências que antecederam O Nascimento da Tragédia. Em duas delas, a antítese Apolo-Dioniso ainda não aparece explicitamente.

Em O drama musical grego, de janeiro de1870, não há referência a Apolo e o fenômeno do dionisíaco é ligado ao impulso primaveril, que surge e intensifica as forças vitais. A origem asiática de Dioniso e seu aspecto destrutivo que precisa ser dominado ainda não aparecem nesta obra, que revela o dionisíaco a partir dos cortejos da Grécia antiga, que deram origem à tragédia.

A noção de "claridade apolínea" surge no texto chamado Sócrates e a Tragédia, de fevereiro do mesmo ano. Esta é encarnada em Sócrates e vista como um aspecto crucial do mundo helênico. A menção a Sócrates marca o nascimento da ciência grega e, simultaneamente, a recusa do mundo trágico antigo através da moralização da própria tragédia. Esse é o "instinto" ou "impulso socrático" considerado longamente depois no Crepúsculo dos Ídolos. Com o uso mais regular do termo instinto ele parece expor ironicamente o caráter de abelha de Sócrates, cujo remédio para a vida é o que proporciona o mel de uma verdade unívoca: o supremo bem. A necessidade de verdade é o sintoma do medo da indeterminação, conduz à rigidez da Cultura moderna e mantém um quasi instinto, o ideal de verdade, que surge para combater a pluralidade de tendências e alvos de impulso.

$\mathrm{Na}$ terceira dessas conferências inaugurais, A Visão Dionisíaca do Mundo, a oposição Apolo-Dioniso é finalmente explicitada como dupla fonte original da tragédia. Apolo ganha definição e função como deus da arte e das representações oníricas. A essência de Apolo é a medida, a limitação, a sabedoria, a calma, a bela aparência. Em contraposição, Dioniso é o deus da embriaguez e da desmesura, rompe todas as barreiras harmonizando as diferenças na comunhão dos coros báquicos. Pela maneira como apresenta os deuses míticos nesse texto, fica mais claro como o filósofo recebe a conhecida influência de Bachofen (do ponto de vista simbólico) e Creuzer (do ponto de vista etnológico): Nesse mundo grego de harmonia e beleza apolínea e artificial representados na lira de Apolo, irrompe a flauta selvagem da música dionisíaca; em contraposição, a festividade na qual aparece o manancial dionisíaco trácio, é convertida entre os gregos em uma orgia 
idealizada, e finalmente em tragédia, pois o culto a Dioniso encontra entre os gregos uma sensibilidade mais refinada e a capacidade maior para o sofrimento e para o pessimismo. Apolo salva a Grécia da influência bruta do Dioniso oriental, envolvendo-o no véu delicado de uma bela aparência. Assim, tanto um impulso como o outro podem crescer livremente na tragédia, onde os enigmas e terrores dionisíacos vivenciados pelas pessoas podiam ser expressos na música trágica, e envolvidos em plasticidade apolínea.

Surge aí um pessimismo ativo, um pessimismo de força, capaz de afirmar a existência do mundo em sua radicalidade, por assim dizer enlaçando o terrível dionisíaco sob o manto da beleza apolínea.. Nele a infelicidade não é um castigo, mas uma contingência imponderável que não se relaciona diretamente aos possíveis méritos de um indivíduo, tal como Sófocles expõe no Édipo Rei, por exemplo.

Em Nietzsche, a essência do trágico é o sofrimento inocente. Para ele, a tragédia é uma transfiguração do sofrimento, entendido como uma domesticação e uma espiritualização dos impulsos violentos, selvagens, capazes de destruir a humanidade do homem. $\mathrm{Na}$ obra de arte, vemos a atividade preparatória de dois impulsos. No breve encontro entre Apolo e Dioniso se dá a união de dois princípios, cujos efeitos são incomensuráveis, e que tem seu ponto culminante na obra realizada, voltando depois a se separar, cada um encontrando na própria potência o radicalismo de uma posição antagônica (cf. FP de fim de 1870-abril de 1871 7[72]).

Tal posição surge para o próprio Nietzsche como qualquer coisa diferente da visão do trágico como resignação e negação da vida, que lhe parece ecoar na visão de conjunto da filosofia de Schopenhauer. Mas, há na transfiguração que Nietzsche pretende promover no pessimismo, a consideração de um aspecto já presente no filósofo da Vontade: "A tragédia (Tranerspiel) exige (fordet) uma existência diferente (anderartiges Dasein), outro mundo (andere Welt), a cujo conhecimento nós chegamos apenas de maneira indireta" ", proporcionado pelo sentimento que a tragédia desperta. Apenas acontece que esse mundo diferente não aparece em Nietzsche definido como uma negação resignada, mas sim como um refinamento dos alvos pulsionais, pois a visão do mundo a partir desse viés não admite a conclusão de que "o verdadeiro destino da existência humana é a dor”.

11 SCHOPENHAUER, A. SW, II, p. 815-6. 
A vida humana é considerada, nesse momento inaugural, tanto como uma "tendência trágica" (tragische Tenden`) quanto como uma "penosa cura" (peinliche Kur), que nos purga das ilusões da vida e que acaba, a partir disto, tornando-se benéfica ${ }^{12}$.

O que não temos certeza, a partir disso, é se a conclusão oposta à de Schopenhauer é tão diferente assim em termos práticos, isto é, quanto ao funcionamento pulsional, suas características e efeitos, ou se é um problema de acentuação de características que, ao final, precisaria ser solucionado em algum tipo de síntese na experiência do indivíduo na medida em que a afirmação ou negação da Vontade em Schopenhauer não são prescritivas, mas sim dependem da experiência e do julgamento da vontade individual que contempla a si mesma no espelho da representação. Se tivermos em mira que a atitude ascética é uma espécie de "caminho da salvação" para a Vontade, não seria isso um refinamento do próprio impulso (Trieb) liberto de suas ilusões? Um caminho, portanto, sublime, porém pintado com as cores de um temperamento forte e que necessitava de demônios e dragões para combater, elegendo, afinal, a própria vida como inimiga Embora a filosofia de Schopenhauer não acentue a "alegria desinteressada" como uma sublimação do impulso, isto já está implícito no paradoxo percebido nas posições do autor da metafisica da sexualidade em contraste com o que aparece na metafísica do belo. Mas, até mesmo quando Schopenhauer fala acerca do puro sujeito do conhecimento, o faz nos seguintes termos:

Somente quando a vontade com os seus interesses abandona a consciência e o intelecto livremente segue suas próprias leis, e como sujeito puro espelha o mundo objetivo, ainda que a partir de seus próprios impulsos [Triebe] esteja no mais alto estado de tensão e de atividade, instigado pelo não querer, só então a cor e a forma das coisas se destacam em seu verdadeiro e pleno significado (SCHOPENHAUER, MVR II 30).

É inegável que essa passagem elucida um importante ponto de discussão eterna a respeito do que significaria afinal a supressão da vontade do psiquismo, pois sempre, pelas análises convencionais, a coisa toda parece um exagero místico, quando, na verdade, trata-se apenas de sublimação do impulso, a partir de que o querer-viver encontra alvos mais sutis, fluidos, e que alcançam seus alvos sem a resistência que provoca o sintoma ou

12 Idem, p. 815-6.

Estudos Nietzsche, Curitiba, v. 4, n. 1, p. 25-42, jan./jun. 2013 
a satisfação direta. Nietzsche é talvez o primeiro a perceber o valor da resistência para a pletora do impulso, e, por isso também, muito tempo depois Freud vai escrever que a satisfação direta de um impulso tem um valor incomparavelmente maior do que a satisfação sublimada, mas que, no entanto, tudo o que se construiu na cultura, todas as coisas que amamos na arte e no conjunto das relações humanas, não teria sido possível sem essa propriedade fundamental do impulso: perseguir a satisfação por outros fins por outros meios. Ao final, se o objeto e o modo de satisfação variam, ainda assim o impulso é sereno pela atividade redentora e eficaz que produz a sublimação. E um importante detalhe acerca disso, é que a satisfação sublimada utiliza uma energia ou libido que de outro modo seria utilizada para fins sintomáticos, na medida em que na maioria das vezes o caminho para a satisfação direta está barrado por inúmeros fatores. Desse modo, é mais o caso de esclarecer Schopenhauer e de certo modo rir de seus exageros, do que propriamente o combater. Penso inclusive que, na maior parte dos casos, Nietzsche dirige suas críticas mais aos seguidores de Schopenhauer, seus apóstolos dos primeiros tempos, do que propriamente ao filósofo da Vontade. Nietzsche não podia cair na vala comum, na medida em que ouviu de Schopenhauer coisas que o levaram a constituir a sua própria filosofia com independência, tal como é preconizado pelo filósofo de Frankfurt em suas críticas à filosofia universitária, de que tratarei em outro artigo paralelo.

\section{$* * *$}

O curioso é como essa tensão existente entre os dois autores, Nietzsche e Schopenhauer, e interna também à filosofia deste último, reaparece na psicanálise contemporânea ${ }^{13}$, através das leituras e nuances proporcionadas pelo pensamento freudiano junto aos nossos contemporâneos, tanto nas tendências clínicas que acentuam a falta, quanto naquelas que acentuam o processo de diferenciação dos impulsos e uma intensificação da experiência, ou pelo menos, como uma variação dessa segunda tendência, também aquelas que visam um aprimoramento da experiência de vida através da revelação do inconsciente. Tais coisas ressurgem, aliás, também na demanda dos analisandos contemporâneos, que partem para a aventura da análise buscando uma "existência diferente", "outro mundo", um "não-sei-que"

13 HERZOG, R. Desconstruindo a razão: de Schopenhauer a Freud. In: A psicanálise e o pensamento moderno, p. 79. 
dado imediatamente ou o mais rápido possível, para se livrarem da angústia e do sofrimento existencial. Curioso também como essa intensificação, no caso de Nietzsche, não é definida por ele como uma questão de otimismo ou pessimismo, mas como uma parte importante da própria natureza do impulso, necessitando, portanto, de contínua reinterpretação.

Porém, para sermos justos com Schopenhauer, devemos ressaltar novamente que ele não prescreve a negação, pois sequer considera que tal coisa seja possível na prática, pois tudo ocorre através da espontaneidade como uma conversão, tal como já está dito desde os seus diálogos com Goethe que resultaram no texto Sobre a visão e as cores.

O foco de Schopenhauer foi distorcido pelos seus seguidores e certamente isso serviu a Nietzsche, na medida em que optou pelo caminho inverso, o que resulta no seu perspectivismo e na sua ainda mal compreendida doutrina da vontade de potência.

Como evidenciei na citação destacada no meu texto, Schopenhauer elogia a negação do querer ligado ao eu, ao egoísmo, e, nesse sentido, ainda há margem para uma forma de afirmação da vida, para aquele que puder suportar o fardo da existência, e, certamente, há margem para a sublimação, supremo alívio para um homem de caráter forte, que poderia assim falar sobre uma forma de se libertar por um instante da opressão da lei do tirano Eros. Esse ponto da psicologia do filósofo é analisado na segunda dissertação da Genealogia da Moral.

Falta talvez a Schopenhauer, por ter sido uma obra em tudo inaugural na história da filosofia, especialmente devido ao seu caráter pulsional, certa clareza acerca do que ele próprio engendrou. E parece que ele até mesmo entra em contradição quando admite que a vontade age através de muitos artistas e, simultaneamente, acredita na supressão momentânea do querer através do fenômeno estético, e, mais ainda, acredita também que isso possa se dar de modo permanente, ainda que precise ser sustentada através de suplícios, que é característica própria ao modo como o asceta combate a sua própria condição de ser desejante. No entanto, é bom lembrar, tudo isso só ocorre após um momento de transfiguração do ser, seja através de um satori, de uma iluminação, de uma revelação, ou de uma conversão do egoísmo em compaixão. Não é para quem quer, é para quem pode. Se é que pode, pois, não se trata de uma experiência do próprio Schopenhauer. Por isso Nietzsche o acusa de exageros místicos. 
Há um aspecto da compaixão que não é suficientemente considerado por Nietzsche e que nos parece fundamental para o reconhecimento de nossa humanidade. Trata-se da identificaşão com os nossos semelhantes, que nos impede de sermos todos sociopatas. Não se trata apenas de piedade. Parece que Schopenhauer está bastante consciente disso quando contrapõe o egoísmo à compaixão. No entanto, Nietzsche escarnece disso e abre contingência para abusos de sua filosofia como o livro editado por sua irmã sob o título de Vontade de potência. Isso só evidencia que todos temos pontos fracos nos pontos em que o nosso pensamento se torna mais obscuro e a nossa letra se torna mais ambígua e dilacerada pela insuficiência da linguagem. É justamente nisso que Schopenhauer se apoia para criticar Hegel, mas nem ele, nem Nietzsche, nem ninguém pode se livrar dessa sina, especialmente um filósofo que, necessariamente, deverá escrever nos limites de sua consciência possível, isto é, nos limites de sua percepção e condição intelectual, e que, por mais ampla e profunda que estas sejam, encontrará seu ocaso como o dia ao entardecer. E, nesse entardecer da racionalidade, o lusco-fusco do efetivo misturado ao imaginário associado às sombras adejantes que antecedem a noite do inconsciente começa a se manifestar invariavelmente, escarnecendo de nossa racionalidade, pregando peças.

No entanto, ressalte-se que nos parece que Nietzsche teme de um modo bem prático a perda do elemento bravio e originário da condição humana, o desejo de superar dificuldades e impor provisoriamente um predomínio de certas forças sobre outras forças, que também pode ser concebida como uma hierarquia de inteligências ou de tendências de nosso comportamento. A compaixão envenenaria as pessoas tornando-as dóceis e manipuláveis, um rebanho, coisa que já está expressa na parábola dos porcosespinhos do livro Parerga e Paralipomena, de Schopenhauer, citada também por Freud em Psicologia de Massas e Análise do Eu.

Todas essas variações em torno do tema dos impulsos inconscientes de nosso psiquismo, que implicam em diferentes posições acerca da ética, da estética e do conhecimento, resultam na valorização da interpretação que propõe uma hermenêutica do conhecimento, como está expresso no aforismo 116 do segundo livro de Aurora:

O que é tão difícil para os homens compreenderem, dos mais remotos tempos até hoje, é sua ignorância sobre si mesmos. (...) Não é justamente isso a "terrível" verdade: que o que se pode saber de uma ação não basta jamais para fazê-la, que a ponte do conhecimento ao ato não foi lançada nenhuma vez até hoje? (A 116) 
Também em Schopenhauer isto se dá de modo semelhante. Por mais que o querer nos pareça ser fundamentado em um motivo, este é submetido à impetuosidade íntima (o Drang do impulso) e à ausência de uma causa última que justifique o querer (Wollen) em si. Assim, é apenas a construção intelectual que confere sentido à representação de um querer consciente, quando, por exemplo, alguém se desloca até um objeto e o pega.

Apesar do alvo momentâneo que surge então, não temos como avaliar a possibilidade de permanência e nem o sentido do querer a partir de um motivo. O ímpeto está liberto de um alvo necessário no mundo, ou seja, não existe uma relação necessária de causa e efeito entre ação e motivação ${ }^{14}$.

A constatação do desamparo do ser humano é radical em ambos os autores, pois em nenhum deles aparece a imagem redentora de um pai cósmico que olha por nós, mas os tesouros que ambos acumularam no interior de suas filosofias, de certo modo com tanta afinidade, ainda que radicalmente diferentes no modo como acolhem a finitude e a degradação de tudo o que existe no universo, produzem um movimento pendular entre a afirmação e a negação do querer-viver. No ponto extremo dessas tendências, a primeira polaridade nos conduz ao herói trágico, e a segunda ao asceta. Mas, é o próprio Nietzsche quem pergunta: O que significa o ideal ascético para um filósofo? E ele mesmo responde:

O filósofo sorri ao seu encontro, como a um optimum das condições da mais alta e ousada espiritualidade - ele não nega com isto "a existência", antes afirma a sua existência, apenas a sua existência, e isso ao ponto de não lhe ser estranho este desejo perverso:pereat mundus, fiat philosophia, fiat philosophus, fiam!...(GM III, 7)

Para este filósofo, no ideal ascético são indicadas tantas pontes para a independência, que um filósofo como Schopenhauer não conseguiria ouvir sem júbilo e aplauso interior a fabulosa história dos homens resolutos que um dia disseram não a toda servidão e foram atrás de um deserto para enfrentar o próprio desejo como se este fosse um demônio. O que

14 Curiosamente, será esse mesmo argumento schopenhaueriano que Nietzsche usará para questionar, por exemplo, na Genealogia da Moral, a estética e a ascese como formas de libertação do querer: Para este filósofo, a sublimação do querer através da arte e da moral, na maneira como Schopenhauer entende a polaridade da negação nos Livros III e IV de O Mundo, são ainda uma refinada vontade. Esta já não aparece como anulação do querer, mas sim, na sutilização do ímpeto insaciável, ressurge como impulso de conhecimento.

Estudos Nietzsche, Curitiba, v. 4, n. 1, p. 25-42, jan./jun. 2013 
minimamente precisa um homem, perguntaram eles? Parece que Nietzsche esteve bastante interessado não apenas no preço a ser pago em termos de vitalidade, do ponto de vista de uma depreciação do corpo e da sexualidade a ele associada, mas também do ponto de vista da mensagem passada pelas formas de pessimismo teórico que são associadas à Verneinung. Ainda que possamos dizer de Schopenhauer que o seu próprio filosofar implique num otimismo prático, na medida em que o filósofo se dirige às pessoas, e escreve inclusive Aforismos para a sabedoria de Vida, Nietzsche pode, ainda assim, sentir muito bem o odor cadavérico das flores schopenhauerianas atraindo os abutres e hienas de sua época e o perigo que o pessimismo teórico representa em termos práticos para os depressivos e os inimigos da vida de um modo geral. Trata-se, inclusive, de uma condenável forma de sedução para os homens doentes e para os deserdados da sociedade, que já teriam motivos de sobra para a negação da vida, na medida em que a vida estaria se negando a eles de modo tão enfático também. O próprio autor de Aurora se considerava um homem espiritualmente sadio num corpo doente, e necessitou superar sua condição doentia através da própria filosofia; pareceu-lhe realmente fundamental cantar um outro canto; não aquele canto de criaturas descontentes, a redenção de pessimista e do ressentido, mas uma ária de louvor à superação das condições atuais de existência, uma canção afirmativa, uma ode à vida, ainda que em meio à transitoriedade, da dor e do sofrimento inerentes ao dito fenômeno.

\section{Referências}

ANDLER, C. Nietzsche sa vie et sa pensée. Paris: Gallimard, 1958.

ASSOUN. P-L. Freud et Nietzsche. Paris : PUF, 2005.

CACCIOLA, Maria Lúcia Oliveira e Mello. Schopenhauer e a questão do dogmatismo. São Paulo: Editora da USP, 1994.

DIAS, R. M. Um Dioniso bárbaro e um Dioniso Civilizado no Pensamento do Jovem Nietzsche. In: Encontros Nietzssche. Ijuí: Ed. Unijuí, 2003.

FREUD, S. Die S Freud-Studienausgabe. S. Fischer Verlag, 1980. Org., 11 vols., Munique, DTV/ de Gruyter, $2^{a}$ ed., 1999. 
JANZ, C. P. Friederich Nietzsche. 1. Infancia y juventud. Madrid: Alianza Editorial, S. A., 1994.

NIETZSCHE, F. Kritische Studienausgabe. Org. Giorgio Colli e Mazzino Montinari, 15 vols., Munique, DTV/ de Gruyter, $2^{\mathrm{a}}$ ed., 1999.

NIETZSCHE, F. Werke. Berlin; New York: de Gruyter, 1982.

NIETZSCHE, F. Aurora. São Paulo: Companhia das Letras, 2004.

NIETZSCHE, F. A Gaia Ciência. São Paulo: Companhia das Letras, 2001.

NIETZSCHE, F. Genealogia da Moral - uma polêmica. São Paulo: Companhia das Letras, 1998.

NIETZSCHE, F. Ecce Homo - Como alguém se torna o que é. São Paulo: Companhia das Letras, 2005. KOWALEWSKI, A. Arthur Schopenhauer und seine Weltanschauung. Königsberg: Carl Marhold Verlagsbuchhandlung, 1908. MALTER, R. Arthur Schopenhauer: Transzendentalphilosophie und Melaphysik des Willens. Stuttgart-Bad Cannstatt, Frommann-holzboog. 1991. METHLING, A. Das Realitätsproblem im Denken Schopenhauers - Eine Untersuchung zur Struktur seines Systems. Köln: Shaker, 1993.

SCHOPENHAUER, A. Sämtliche Werke, ed.Wolfgang Frhr. von Löhneysen, Frankfurt, 1986, 5 vols.

SCHOPENHAUER, A. Schopenhauers Sämtliche Werke, Piper Verlag, München 1911-1926, Bd. I-VI.

SCHOPENHAUER, A. Die Welt als Wille und Vorstellung, Ergänzungen, [O Mundo Como Vontade e Representação: Complementos] - 1844 (2 a. ed.); 1859 (3a. ed).

SCHOPENHAUER, A. Über den Willen in der Natur, Sobre a Vontade na Natureza - 1836.

Recebido: 03/11/2012

Received: 11/03/2012

Aprovado: 06/01/2013

Approved: 01/06/2013 